\title{
LANGUAGE AND THE HAVING OF CONCEPTS
}

\author{
MILTON FISK
}

$\$ 5$ (iii)* From 4.2, which is the definition of concept-having now under discussion, it follows that having the concept red entails having a certain linguistic ability. But from the nonverbal thought difficulty, whose genuineness was established in (i), it follows that the exercise of a concept does not entail the exercise of a linguistic ability. Now, on the one hand, where we have an entailment from one ability to another we generally have a corresponding entailment regarding the exercise of these abilities. If having an ability to write with a typewriter entails the possession of a manual skill, then the exercise of an ability to write with a typewriter entails the exercise of a manual skill. On the other hand, where we have a non-necessary implication from one ability to another we do not have an entailment regarding the exercise of these abilities. According to the naturalist, an ability to cut with teeth implies an ability to tear with claws. But every instance in which an animal's teeth do a job of cutting neither must be nor is an instance in which its claws do a job of tearing. The nonverbal thought difficulty would, then, seem to call for a denial of the entailment from concept-having to linguistic ability. Moreover, not only would it seem that 'concept' and 'linguistic ability', as used in 'has'-contexts, do not have the same meaning, but it would also seem that 'concept' and 'linguistic ability', as used in 'has'-contexts, do not apply to the same ability. This further consequence follows from the fact (cf. (i)) of there being instances, not just the possibility of instances, of nonverbal thought. Since concepts are sometimes exercised without an accompanying linguistic exercise, concepts, even if we call them abilities, are distinct from linguistic abilities. For otherwise, if 'concept' and 'linguistic ability' apply to an identical ability, an exercise of that ability would be equally a conceptual and a linguistic activity, contrary to the fact of nonverbal thought.

But such a line of reasoning is not the only one available in an attempt to judge the effect of the nonverbal thought difficulty on the entailment from concept-having to linguistic ability. No account has been taken

\footnotetext{
*The first part of this paper appeared in the Notre Dame Journal of Formal Logic, vol. II (1961), pp. 41-57.
} 
of the fact that some abilities are many-sided, ${ }^{13}$ in the sense that the possession of one of these abilities entails the possession of more than one other ability. Thus:

$A$ is a many-sided ability there is a set of abilities $A_{1}, A_{2}, \ldots$, $A_{n}$ such that more than one of these abilities is not identical with $A$ and such that $A$ entails $A_{1}$ and $A_{2}$ and ... and $A_{n}$.

By contrast, if $B$ is a generic ability comprising the multiplicity of specific abilities $B_{1}, B_{2}, \ldots, B_{n}$, then $B$ entails $B_{1}$ or $B_{2}$ or $\ldots$ or $B_{n}$. Nevertheless, it is clear that numerous ability words function both as generic and as signifying many-sided abilities. Two further definitions will facilitate subsequent discussion:

$A$ is a many-sided ability at the level of $A_{i}={ }_{\mathrm{df}} A$ and $A_{i}$ are abilities and there is an ability $A_{k}$ such that $A$ entails both $A_{i}$ and $A_{k}$ and such that $A_{i}$ neither entails nor is entailed by $A_{k}$.

$A_{k}$ is an ability at the level of $A_{i}$ in respect to $A={ }_{\mathrm{df}} A, A_{i}$, and $A_{k}$ are abilities, $A$ entails both $A_{i}$ and $A_{k}$, and $A_{i}$ neither entails nor is entailed by $A_{k}$.

E.g., if having a certain concept entails having a linguistic ability and, in addition, having only those abilities entailed by a linguistic ability, then that concept will not be many-sided at the level of linguistic ability, even though it will be many-sided if a linguistic ability is many-sided. Or, if having a certain concept entails having a linguistic ability and having an ability to form part of a nonverbal thought, where it is supposed that neither of these abilities entails the other (cf. infra), then that concept is manysided at the level of linguistic ability and the ability to form part of a nonverbal thought is at the level of linguistic ability in respect to a concept.

The consideration of many-sided abilities makes clear the possibility that one ability should entail another while an exercise of the first does not entail an exercise of the second. The word 'scholar' has the characteristics of a many-sided ability word; being a scholar involves an ability to gather information and also an ability to draw conclusions from sources consulted. Yet in the course of scholarly activity conclusions may be drawn while the scholar is not gathering information, and reading at the stage of information gathering may go on for quite some time before the process of drawing conclusions begins. Hence we propose the following general principle:

$\mathrm{P}$ If $A$ is many-sided at the level of $A_{i}$ and if $A_{k}$ is at the level of $A_{i}$ in respect to $A$, then an exercise of $A$ does not entail an exercise of $A_{i}$ and it does not entail an exercise of $A_{k}$, although it entails an exercise of at least one (unspecified) ability at the level of $A_{i}$ in respect to $A$.

Note, on the one hand, that 4.2 rests on the supposition that a concept is not many-sided at the level of linguistic ability. For only on such a 
supposition could the two be identified. Thus, if there are concepts which are many-sided at the level of linguistic ability, then having such concepts cannot be defined in the manner of 4.2. Note, on the other hand, that a concept-to-language entailment as derived from 4.2, and hence from a notion of concepts as other than many-sided, does not hold in the face of the nonverbal thought difficulty. In this case the criticism appealed to in the first paragraph of this sub-section is conclusive. Thus, whether concepts are many-sided at the level of linguistic ability or not, 4.2 must be abandoned. Now, since the question being raised in this sub-section concerns the compatibility of the assumption of a concept-to-language entailment with nonverbal thought, we need not ask whether there are concepts which are many-sided at the level of linguistic ability but only whether, on the assumption of a concept-to-language entailment, there would be concepts which are many-sided at the level of linguistic ability.

Consider this hypothetical illustration concerning the concept beavy. It is agreed that John uses the term 'heavy' correctly. He stands before a large article of furniture commenting that it is extremely heavy and perhaps also that he may need assistance in lifting it into the adjoining room. Yet, in beginning to move it he does not adopt the stance of a man preparing to exert his last ounce of strength; fully erect and with one hand in his pocket he seizes the edge of the top surface between his thumb and forefinger, as if he were picking up an envelope. Failing, he backs away to survey the situation with an air of frustration. In refusing, as I think most of us would, to say that John has the concept beavy, we would imply acceptance of the thesis that having such a concept entails being disposed, under specified circumstances, to act overtly in a manner which is appropriate in respect to the fact that the concept heavy would be correctly applied to some constituent of those circumstances. On further examination we find that even the having of concepts corresponding to the syncategorematics of ordinary languages entails abilities for appropriate nonlinguistic actions. Suppose that John is known to make correct use of statements constructed with 'ifthen'. He refuses to assent to a hypothetical whose consequent he denies and whose antecedent he affirms. Suppose also that he has the concepts corresponding to 'unsupported' and 'fall'. He remarks that, if an object is unsupported, then it will fall. Upon doing so he releases his cup and saucer. So, even though his manner of talking is consistent with the customary meaning of 'if-then', he acts as though he thought a hypothetical were true when its consequent is false and its antecedent true. When his cup and saucer fall into his lap, he does not respond by denying his original assertion that what is unsupported falls. If asked he would say that what has happened confirms his original assertion. Since he talks as though he believed that unsupported objects fall, his surprise will not be due to his having discovered that his original statement is false. Nevertheless, since he acts as though he believed unsupported objects do not fall, he will, we can imagine, register surprise on being confronted with the falling of an unsupported object, even though he will not be able to say why he is surprised. From similar illustrations it could be concluded 
that in a great number of cases concept-having entails being disposed to act in appropriate nonlinguistic ways.

But in order to show that, on the assumption that concept-having entails linguistic ability, concepts are many-sided at the level of linguistic ability this is not sufficient. We must also show that an ability to use a term and a disposition to act in a certain nonlinguistic way do not entail one another. From the illustration involving John and the heavy article of fumiture it is clear that having a linguistic ability does not entail being disposed to act in appropriate nonlinguistic ways. Conversely, John might be disposed to handle heavy objects in appropriate ways without being able to use 'heavy' or any synonym. Thus, on the assumption mentioned, being disposed to act in appropriate nonlinguistic ways is, in a great number of cases, at the level of linguistic ability in respect to concepts. It then follows that, on the same assumption, concepts are, in a great number of cases, many-sided at the level of linguistic ability, in view of this disposition to act in appropriate overt nonlinguistic ways.

Now we return to the nonverbal thought difficulty. Can it be shown, on the assumption of the concept-to-language entailment, that an ability to form parts of nonverbal thoughts is ever at the level of linguistic ability in respect to concepts? If so, then it is clear, in view of $P$, that the assumption of the concept-to-language entailment is not incompatible with the fact that on some occasions concepts are exercised nonverbally. The question just raised will be answered in two steps. (a) It will first be shown that, if there is nonverbal thought, some concepts are such that having them entails being able to form parts of nonverbal thoughts. (b) It will then be shown that being able to form parts of nonverbal thoughts neither entails nor is entailed by a linguistic ability.

(a) Suppose it were maintained that a concept possessed by a person who cannot conduct thought nonverbally is not essentially different from a concept which someone else exercises in nonverbal thought. Thus the latter concept implies, without entailing, an ability to form part of a nonverbal conceptual thought. It differs from the former in the accidental respect of being sufficient for a further task, just as a sharp knife differs from a dull one in the accidental respect of being an instrument which can be used to whittle hard woods. Thus, if there is nonverbal thought, we are not warranted in saying that the phrase 'to have a concept' has two meanings, one containing the notion of being able to form part of a nonverbal thought and the other not containing this notion.

But there is a difficulty. If a concept is exercised, then at least one of the capacities whose possession is entailed by the having of that concept is exercised. Now if in exercising a concept one forms part of a nonverbal thought one will also exercise some other ability, since it is supposed that the ability to form part of such a thought is never entailed by having a concept. But when you think conceptually and nonverbally is there, over and above this thinking, always some other conceptual activity in which you are engaged? You cannot have a nonverbal thought which is also verbal, and you need not always act in some way corresponding to 
your nonverbal thought while you are thinking that thought. Possibly there are other things you might do. But it is clear that you could, on any occasion, make nonverbal thought your only conceptual activity. But then it follows that the concepts you exercise in nonverbal thought entail, not just imply, abilities to form parts of nonverbal thoughts. The analogy between concepts which can and those which cannot be used in forming parts of nonverbal thoughts, on the one hand, and sharp and dull knives, on the other hand, breaks down.

(b) By our definition, one ability is at the level of another in respect to a third only if the first neither entails nor is entailed by the second. Since a language user need not be able to form parts of nonverbal thoughts, it seems clear that an ability to use a term does not entail an ability to form parts of nonverbal thoughts. Yet it is not immediately clear that the converse entailment does not hold. To show that it does not we argue as follows. A linguistic ability is not generic in respect to an ability to form parts of nonverbal thoughts. So, one will regard the second as entailing the first only if he treats a linguistic ability as a facet of a many-sided nonverbal ability. But it is impossible to treat a linguistic ability in this manner. If a linguistic ability is a facet of a many-sided nonlinguistic one, then every exercise of the latter need not be an exercise of the former. Yet a difficulty arises in connection with the following principle. It must be possible that on some occasion an exercise of ability $A$ can be an exercise of an ability $B$, when ability $A$ entails ability $B$. Thus it must be possible that on some occasion when one exercises an ability to form parts of nonverbal thoughts one by that fact exercises a verbal ability. However, when one forms part of a nonverbal thought one cannot do so by using words, for otherwise the thought would be verbal. Hence, without denying that a linguistic ability is in fact a necessary condition for an ability to form parts of nonverbal thoughts, we shall deny that the former is entailed by the latter.

Because of the importance of this conclusion a word must be said in justification of the principle appealed to in our argument. Must it be the case that, if ability $A$ entails ability $B$, at least on some occasion an exercise of $A$ can be an exercise of $B$ ? Our case for an affirmative answer to this question will rest on the following interpretation of the entailment relation between abilities. To assert that John's having ability $A$ entails his having ability $B$ is to assert that what is meant by saying that John has ability $A$ is that the ability he has can, at least partially, be described as the ability $B$. But it is not to assert that part at least of what is meant by saying that John has an ability $A$ is that, even though $A$ does not have the characteristics of $B$, John has an ability other than $A$ which is called $B$. That is, when one asserts that John's having $A$ entails his having $B$, one is asserting that ability $A$ must have the characteristics of ability $B$, not that in having $A$ which does not have the characteristics of $B$ John also has $B$. But if an exercise of $A$ can never be an exercise of $B, A$ does not have the characteristics of $B ; A$ and $B$ are then two different abilities. If there is no occasion on which an exercise of $A$ could be an exercise of $B$, ability $A$ does not entail ability $B$. 
On the assumption of the concept-to-language entailment, it follows from (a) and (b) that, for those thinkers for whom nonverbal thought is possible, having an ability to form parts of nonverbal thoughts is at the level of linguistic ability in respect to concepts. Hence, under the same qualifications, concepts are many-sided at the level of linguistic ability in view of this nonverbal ability for forming parts of inward thoughts. Thus the assumption of the concept-to-language entailment is not incompatible with the fact that on some occasions concepts are exercised nonverbally. There is, however, no necessity either that all conceptualizers should be able to conduct trains of nonverbal thought or that those who can should be able to exercise all of their concepts nonverbally. There may, then, be cases in which the many-sidedness of a concept at the level of linguistic ability is not due to an ability to form parts of nonverbal thoughts. But in such cases the nonverbal thought difficulty simply cannot arise.

(iv) If the having of a concept is to be analyzed in the manner of 4.2, then it follows that having an ability to use a term entails having a concept. But from the language-without-thought difficulty it follows that an exercise of a linguistic ability does not entail the exercise of a concept. We shall show that, under special circumstances, these consequences can be reconciled. Two cases are to be investigated. First, consider the case of a concept which is many-sided at the level of linguistic ability. Then, by definition of many-sidedness at a certain level, having a linguistic ability does not entail having such a concept. In such a case we do not attempt to reconcile language without thought with the language-to-concept entailment, since the assumption of such an entailment is already seen to be false. Second, consider the case of a concept which is not manysided at the level of linguistic ability. Now we cannot hold that a concept of this kind entails and is entailed by a linguistic ability. For otherwise there could be no use of language without a conceptual exercise. Thus, in order to save the language-to-concept entailment, the converse entailment, like the one saved in (iii), must be rejected. To reconcile the language-to-concept entailment with an instance of language without thought it suffices to show that, at the level of concepts, the linguistic abilities in question are many-sided. As was just shown the concepts in question cannot be many-sided at the level of linguistic ability, but they may yet be many-sided in other respects. But, if the intended reconciliation is made in the manner just indicated, it follows that any ability entailed by the concepts in question is also entailed by some linguistic ability. Noting that, if linguistic abilities are many-sided at the level of concepts, concepts are not many-sided at the level of linguistic abilities, the needed restrictions are gathered together in the following statement: The languageto-concept entailment can be shown to be compatible with an instance of the use of language without thought where linguistic abilities are manysided at the level of concepts.

Now a word concerning the suggestion made in (ii). (a) Does the 'thoughtfully'-proviso enable us to save 4.2? Clearly not. For we cannot reconcile an identification of having a concept and having an ability to 
use a term correctly and thoughtfully, from which it follows that a concept is not many-sided at the level of such an ability to use a term, with nonverbal thought. (b) Is the addition of a 'thoughtfully'-proviso which can be suitably analyzed the only means of preserving a language-to-concept entailment? It is indeed one way, and a way which, unlike the one just proposed, does not require that the linguistic ability be many-sided at the level of concepts. If, in regard to the proposal of the preceding paragraph it can be shown that the condition that a linguistic ability be many-sided at the level of concepts is satisfied in some cases, then the 'thoughtfully'proviso is, in those cases, not necessary for the preservation of the language-to-concept entailment.

In concluding, we note, on the one hand, that the conditions of the occurrence of nonverbal thought are such that nonverbal thought cannot be incompatible with the following entailent:

5.1 That John, a language user, has the concept red entails that John can use correctly some expression in some language which is used in the same way that 'red' is used in English.

The conditions to which we refer were established under (a) and (b) of (iii). It follows from what was established under (a) of (iii) that, if John is capable of nonverbal thought about red things, his having the concept red entails his having an ability to form those parts of nonverbal thoughts which make them thoughts about red things. And it follows from what was established under (b) of (iii) that having such a nonverbal ability neither entails nor is entailed by having an ability to use 'red' or some synonym. Thus, if we assume both 5.1 and that John is capable of nonverbal thought about red things, John's exercising the concept red does not, according to $\mathrm{P}$, entail a linguistic performance with 'red' or some synonym. Only if there were such an entailment would an incompatibility arise between 5.1 and nonverbal thought. That there is not such an entailment follows from the fact that assuming both 5.1 and John's capability for nonverbal thought about red things leads to the conclusion that his concept red is many-sided at the level of linguistic ability. But if his concept is assumed to be manysided at the level of linguistic ability, it follows from the definition of being-many-sided-at-the-level-of that the converse of 5.1 cannot be maintained. This suggests that the nonverbal thought difficulty in respect to 4.2 can be located in the breakdown of the entailment from language habits to concepts.

We note, on the other hand, that, if the special condition mentioned in (iv) could be satisfied, the occurrence of language without thought could not be incompatible with the following entailment:

5.2 That John can use correctly some expression in some language which is used in the same way that 'red' is used in English entails that John has the concept red.

For suppose that on some occasions John uses 'red' or some synonym thoughtlessly and that John's ability to use such a word is many-sided at 
the level of the concept red. Then, appealing again to $\mathrm{P}$, it does not follow that when John uses the word thoughtlessly he must exercise the concept red. Only if this did follow would an incompatibility arise between 5.2 and language without thought. If John is capable both of nonverbal thought and of language without thought, it is easy to show that, in respect to John's concept red, both 5.1 and 5.2 cannot be true. For, if they are to be jointly true, a concept must be many-sided at the level of a linguistic ability and the same linguistic ability must be many-sided at the level of that concept. Due to the definition of being-many-sided-at-the-level-of this cannot arise. Moreover, 5.1 and 5.2 will not be simultaneously true when emended by the 'thoughtfully'-proviso, for this would require that a concept be manysided at the level of a linguistic ability and that the same linguistic ability entail that concept.

$\S 6$ In both 4.2 and 5.1, 'red' ' occurs to the right of and 'red' occurs to the left of the main connective. Since it is intended that the expression which when italicized occurs on the left be synonymous with the expression which when quoted occurs on the right, special care must be taken in formulating general statements of which 4.2 and 5.1 are consequences. The discussion here will be limited to the question of formulating a general definition of which 4.2 is a consequence. Analogous considerations would apply to the question of formulating a general entailment of which the more acceptable 5.1 is a consequence.

In order to formulate a general definition the following symbols are introduced. ' $L$ ' and ' $L$ ' will be variables for languages. ' $P$ ' will be a variable ranging over language users. The variables ' $E$ ' and ' $E$ ' are such that instancing in respect to them involves their replacement by nonsentential expressions (cf. $\$ 2$ ) of $L$ and $L^{\prime}$, respectively, in quotes. On the other hand, the variable ' $e$ ' is such that instancing in respect to it involves its replacement by nonsentential expressions in italics, belonging to the language of the context in which it occurs. As a first attempt we lay down the following definition:

6.1 $P$ has the concept $e={ }_{\mathrm{df}}$ there is an $E^{\prime}$ in some language $L^{\prime}$ such that $E^{\prime}$ is used in $L^{\prime}$ in the same way that $E$ is used in $L$ and $P$ can use $E^{\prime}$ correctly.

Since 6.1 is intended to be closed, it will be supposed that $E$ and $L$ are implicitly bound by universal quantifiers placed at the extreme left. But, since no correspondence is required between $e$ and $E$, there are instances of 6.1 which are incorrect (when, e.g., we have 'red' for ' $e$ ' and ' 'green', for ' $E$ '). Two methods are open for remedying this difficulty.

First, one might attempt to write the needed correspondence into 6.1 itself. We would then have the following "conditional definition":

6.2 If $E$ in $L$ means $e$, then $P$ has the concept $e={ }_{\mathrm{df}}$ there is an $E^{\prime}$ in some language $L^{\prime}$ such that $E^{\prime}$ is used in $L^{\prime}$ in the same way that $E$ is used in $L$ and $P$ can use $E^{\prime}$ correctly.

From 6.2 we have by instantiation: 
6.3 If 'rot' in German means red, then John, a language user, has the concept red $=\mathrm{df}$ John can use correctly some expression in some language which is used in the way that 'rot' is used in German.

But because of the absence of a "meaning proviso", neither 4.2 nor the following definition, which is an English translation of a German definition formulated in the manner of 4.2, results from 6.2 by instantiation:

6.4 John, a language user, has the concept red $=\mathrm{df}$ John can use correctly some expression in some language which is used in the way that 'rot' is used in German. 14

Nevertheless, since ' 'red' means red' and ' 'rot' means red' can be known to be true merely on the basis of knowing what the expressions used and quoted in them mean, i.e., since they are true $a$ priori, 4.2 and 6.4 are consequences of two corresponding instantiations of 6.2 and, moreover, 4.2 and 6.4 are each equivalent, despite the absence of a meaning proviso in either, to a corresponding instantiation of 6.2.15

Second, instead of changing the form of 6.1 in order to avoid the difficulty associated with it, one could change the significance of ' $E$ ' (not of ' $E$ '). ' $E$ ' is now to be a variable such that any case of instancing in respect to it involves its replacement only by an expression of $L$ in quotes which expression is used in the same way that the expression is used which in italics is employed in a corresponding instancing in respect to the variable symbol ' $e$ '. But doesn't this amount to the requirement that $E$ in $L$ is to mean $e$ ? Indeed; but now it functions to put a restriction on $E$, while in 6.2 it is the antecedent of a "conditional definition" in which $E$ is (relatively) unrestricted. With $E$ restricted in this manner the difficulty is avoided.

Is there any reason for accepting 6.1 with restricted $E$ rather than 6.2 with unrestricted $E$ ?

(a) It would be a mistake to argue in the following manner that 6.4 , e.g., which lacks a meaning proviso is incorrect and, hence, that the general definition, 6.1, of which it is an instance is incorrect. Consider now, not 6.4 , but $6.4^{*}$ which is like 6.4 except for having 'if and only if' in place of ' $=\mathrm{df}$ ' of 6.4 . If 6.4 is correct, $6.4^{*}$ is necessarily true. But, since the meanings of 'red' and 'rot' could be unrelated, $6.4^{*}$ is contingently true. Hence, 6.4 is incorrect.

Two senses of contingency are involved, but not distinguished, in this argument. First, a statement is contingently true only if it could not be determined that it is true solely by consideration of the meanings of its terms ("factually" contingent). Second, a statement is contingently true in respect to a given term only if it could become false upon changing the meaning of that term ("significationally" contingent). The statement "If 'baby' and 'infant' have the same meaning, then Johnny is a baby if he is an infant' is not significationally contingent in respect to 'baby' and 'infant'.

6.4* has been shown, by the above argument, to be only a significationally contingent truth. However, if 6.4 is correct, $6.4^{*}$ cannot be a 
factually contingent truth, but $6.4^{*}$ may be a significationally contingent truth. Thus it does not follow that 6.4 is incorrect. Otherwise every definition without meaning provisos, whether it includes quotations or not, would be incorrect. Thus this claim that 6.1 should be replaced by 6.2 rests on a confusion of senses of contingency.

(b) 6.2 is not a definition of concept-having. 6.2 asserts that 6.1 would be a definition of concept-having, if the meaning proviso were satisfied. In calling 6.2 a "conditional definition" one is apt to overlook this and think of 6.2 as itself a kind of definition. Similar remarks apply to 6.3 in respect to 6.4. There are always requirements which the terms used in framing a definition must satisfy. But to embody these requirements explicitly in the formulation proposed is to formulate a statement to the effect that something could be a definition but it is not to formulate a definition. One is free to choose to define or to avoid defining by stating what would be a definition if certain conditions were fulfilled. But it is clear that in choosing 6.2 one would not be choosing a definition of concept-having. In $\S 4$ our purpose was to attempt to give a definition; thus we chose 4.2 rather than a corresponding "conditional definition". (In $\$ 5$ we chose 5.1 rather than a corresponding "conditional entailment".) It is now appropriate, in order to have the general formulation of which 4.2 is an instance, to choose 6.1 with restricted $E$ rather than to choose 6.2 . In making this choice we note that in stating the restriction on $E$ for 6.1 the phrase 'means $e$ ' was avoided. If this had been impossible, then, by $\S 1,6.1$ could not be understood without circularity. If 6.2 , instead of 6.1 , were chosen, a suitable replacement for 'means $e$ ' would have to be found.

It is instructive to contrast the alternatives which present themselves for a general definition of concept-having, when we restrict ourselves to the program of identifying concepts with language habits, with several variations on a familiar idea as to the definition of truth. Note the analogy between 6.1 and the following:

$\mathrm{U} S$ is true $={ }_{\mathrm{df}} p$.

Assume that ' $S$ ' stands in place of sentences in quotations and that ' $p$ ' stands in place of sentences. Just as $E$ was restricted for $6.1, p$ must be restricted for $U$ in such a way that a sentence can replace $p$ only if it is synonymous with the sentence which in quotations replaces ' $S$ ' in the same in stantiation. If instead of 6.1 we had

V $P$ has the concept $e={ }_{\mathrm{df}}$ there is an $E$ in some language $L$ such that $E$ in $L$ means $e$ and $P$ can use $E$ correctly,

then we would have a definition analogous to

W $S$ is true $=_{\mathrm{df}}$ there is a $p$ such that $\mathrm{S}$ means $p$ and $p$.

The above restrictions on $E$ and $p$ would be unnecessary for definitions $V$ and $W$. But, as noted in the previous paragraph, the clause ' $E$ in $L$ means $e^{\prime}$ is objectionable in a definition of concept-having, just as ' $S$ means $p$ ' 
would be objectionable, if one could not, or would not want to, cope with such a meaning relation in defining truth. Furthermore,

$\mathrm{X}$ If $S$ means $p$, then $S$ is true $={ }_{\mathrm{df}} p$

is like 6.2 in being a "conditional definition". Finally, it is easily shown, where ' $=\mathrm{df}^{\prime}$ is replaced by 'if and only if' in $6.2, \mathrm{X}, \mathrm{V}$, and $\mathrm{W}$ to give 6.2*, $\mathrm{X}^{*}, \mathrm{~V}^{*}$, and $\mathrm{W}^{*}$, that $6.2^{*}$ is not equivalent to $\mathrm{V}^{*}$ and, correspondingly, that $X^{*}$ is not equivalent to $W^{*} .16$

$\$ 7$ A difficulty arises in respect to 5.1 , as well as in respect to 4.2 , which involves the relation of concepts to property descriptions, i.e., phrases such as 'the taste of sugar', 'the color of beets', and 'the shape of John's room'.

In order to state this difficulty we begin by describing two possible situations. (i) Suppose that John is unable to use the adjective 'sweet' or any synonymous adjective. From the general entailment of which 5.1 is an instance it would follow that John does not have the concept sweet. But John might be able to decide the truth value of and to formulate such statements as 'This has the taste of sugar', 'I like the taste of sugar', and 'The taste of sugar is not the same as the taste of salt'. His ability to do this would be taken as evidence of his having the concept the taste of sugar. (ii) Suppose again that John cannot use 'sweet' or any synonym. But now let it be the case that John can decide the truth value of and that he uses the statements 'This has the taste of Aunt Mary's specialty', 'I like the taste of Aunt Mary's specialty', and 'The taste of Aunt Mary's specialty is not the same as the taste of salt'. This would be taken as evidence for his having the concept the taste of Aunt Mary's specialty. Aunt Mary's specialty happens to be sweets.

In regard to (i) it could plausibly be held that either 'This is sweet' or 'This has the property sweet' and 'This has the taste of sugar' entail one another and, hence, that 'the property sweet' and 'the taste of sugar' are synonymous. In regard to (ii) it happens to be true that the property sweet is the same as the taste of Aunt Mary's specialty. But it does not follow from the meanings of the individual terms in 'the taste of Aunt Mary's specialty' that Aunt Mary's specialty must be sweets. Thus the propertyidentity 'The property sweet is the same as the taste of Aunt Mary's specialty' might be false. Because of such a possibility it is clear that the property sweet' and 'the taste of Aunt Mary's specialty' do not have the same meaning. 17 For, when two expressions of such a kind are synonymous, they must apply to the same things. Since, moreover, neither of these expressions is entailed by the other, sweetness is no part of the meaning of 'the taste of Aunt Mary's specialty'. Thus, if Aunt Mary happened to change her specialty so that it is no longer sweets, the meaning of the taste of Aunt Mary's specialty' would remain unchanged even though it would no longer be true that the property sweet is the same as the taste of Aunt Mary's specialty.

Where, as in (i), John cannot use 'sweet' but has the concept the taste 
of sugar and where 'the property sweet' and 'the taste of sugar' are synonyms, it would seem pointless to deny that John has the concept sweet. Indeed, one would not hesitate to attribute the concept sweet to John, if John had shown that he could employ 'the taste of sugar', 'the property sweet', or 'sweetness'. And there would be a similar lack of hesitation in other cases where it would be plausible to claim that statements framed with the property description or the abstract noun in question can be paraphrased by statements formulated with a corresponding adjective. In the particular case under discussion, one's lack of hesitation to say that John has the concept sweet, if there is evidence for his having the concept the taste of sugar, is associated with the fact that such statements as "This has the taste of sugar' and 'The taste of sugar is pleasant' can be paraphrased as 'This is sweet' and 'Anything sweet is pleasant'. Nevertheless, for those who can use 'has the concept ...' correctly, there would be hesitation to attribute the concept the taste of sugar to John on the basis of evidence for his having the concept sweet. It is not our concern here to examine this asymmetry further. But in view of it we cannot lay it down as a general principle that, where the two concepts $A$ and $B$ are not identical but where statements formulated by exercising $A$ can be paraphrased by statements formulated by exercising $B$, having A entails having $B$. That the concept the taste of sugar and the concept sweet are not identical follows from the considerations of $\S 2$ and is related to the fact that the expressions italicized here are not synonyms. Yet even though statements framed in terms of 'sweet' can be paraphrased by statements containing 'the taste of sugar', the hesitation to attribute the concept the taste of sugar on the basis of an attribution of the concept sweet would be sufficient to invalidate the general principle mentioned.

On the other hand, in regard to (ii), there is a reason for denying that having the concept sweet is to be ascribed to John on the basis of the fact that he has the concept the taste of Aunt Mary's specialty. Whether sweets are the specialty or not, the phrase 'the taste of Aunt Mary's specialty' means the same thing, where sameness or difference of meaning is judged on the basis of entailments of statements embodying this expression. Thus we would not speak of the concept the taste of Aunt Mary's specialty as changing when the specialty changes from sweets to something else. There would be no temptation, when Aunt Mary's specialty is not sweets, to infer from John's ability to use 'the taste of Aunt Mary's specialty' or from his having the corresponding concept to his having the concept sweet. But if the inference cannot be made under these circumstances, then it cannot be made when the specialty happens to be sweets since 'the taste of Aunt Mary's specialty' does not change its meaning and the concept the taste of Aunt Mary's specialty is the same concept.

Thus 5.1 stands in need of correction in view of the difficulty which can now be stated as follows. John can have the concept sweet even though he is unable to use 'sweet' or any synonym. His ability to use correctly any expression synonymous with 'the property sweet' is taken as evidence for his having the concept sweet. However, his ability to use an expression 
which happens to refer to the property referred to by 'the property sweet' but which is nonetheless not synonymous with 'the property sweet' is not taken as evidence for his having the concept sweet.

Returning to 5.1, we see that the difficulty in question can be avoided if 5.1 is emended to read as follows:

7.1 That John, a language user, has the concept red entails that John can use correctly some expression in some language which is used in the same way that 'red' or 'the property red' is used in English.

The emended generalized entailment is as follows:

7.2 That $P$ has the concept $e$ entails that there is an $E^{\prime}$ in some language $L^{\prime}$ such that $E^{\prime}$ is used in the same way that $E$ or $F \& G$ is used in $L$ and $P$ can use $E^{\prime}$ correctly. ${ }^{18}$

$E$ is related to $e$ under the restriction on $E$ for 6.1. ' $\&$ ' is a symbol for concatenation which is to be read as 'followed by'. ' $F$ ' is a new variable symbol such that instancing in respect to it involves its replacement by an expression of $L$ which has been placed in quotes and which is used in the same way that 'the property' is used in English. And ' $G$ ' is a new variable symbol such that instancing in respect to it involves its replacement by an expression of $L$ which has been placed in quotes and italics and which is used in the same way that the expression is used which when placed in italics is employed in a corresponding instancing in respect to the variable symbol ' $e$ '.

§8 By way of conclusion brief consideration will be given to two points regarding the interpretation of what has gone before.

There are at least two important uses of the term 'concept'. Our investigation has been concerned with that term only as it occurs in statements such as 'John has the concept red'. However, our results do not apply, at least not directly, to the use of that term in statements reporting philosophical undertakings such as the statement 'Aristotle analyzed the concept change'. A concept as possessed is, generally, a many-sided ability at the level of linguistic ability. A concept as an object of philosophical analysis is not an ability of any sort. For otherwise the philosophical analysis of a concept would consist in an investigation of the conditions under which such a complex of abilities is acquired, of the interaction of such a complex of abilities on other abilities, be they conceptual or not, and of the circumstances which make for the retention and loss of such a complex of abilities. Nevertheless, one can recognize this difference without embracing a dualism according to which the concept as possessed has a concrete, psychological, and real existence while the concept as an object of philosophical analysis has an abstract, immaterial, and intentional existence. There is a relation between the two which, unlike that which would have to be postulated in the context of such a dualism, is not ad boc. In analyzing a concept one studies the uses made of a certain expression and its relatives, that is, one studies the results of exer- 
cises of linguistic abilities which are facets of the corresponding concept as possessed. Thus the concept as possessed generally has facets whose exercise provides uses of expressions which uses become the object of conceptual analysis. From this point of view we do not look for an extralinguistic referent for, say, 'the concept change' in a context such as 'Aristotle analyzed the concept change'. For, if we do and if that referent is not confused with the concept as possessed, then we pose the dualism which makes unintelligible the relationship between the concept as object of analysis and the concept as possessed. Further, if, as we are suggesting, one can understand what is meant by a conceptual analysis only by regarding it as a study of certain results of exercising a concept as possessed, then the use of the term 'concept' in contexts where one speaks of the analysis of concepts is dependent upon or secondary to the use of that term in contexts where one speaks of having concepts. Were it not for overlooking this, those who rightly warn us that conceptual analysis is not psychology would never be led to speak as though conceptual analysis were a descriptive science of the suprasensible.

The second point concerns the failure of 4.2 , or its generalized counterpart 6.1 , as a definition. Is this failure not symptomatic of the fruitlessness of any attempt to define concept-having in terms of abilities? Does it not indicate that we should base our efforts on a literal reading of "has the concept red' according to which 'has' signifies a relation of mental proprietorship and 'the concept red' is an expression denoting an individual of the kind which can be had mentally? Now, first of all, from certain remarks of $\S 5$ (iii) we can infer that, even under restrictions (a) and (b) of $\S 3$ there are many meanings associated with 'has the concept ...'. For, having a concept sometimes, but not always, entails being able to form part of a nonverbal thought. Moreover, if one can speak of having a concept corresponding to an expression of an uninterpreted system, then having such a concept does not entail being disposed to act in appropriate nonlinguistic ways. Such a concept is applied only in situations in which a linguistic performance would be relevant. Thus the failure of 6.1 indicates, among other things, that any single definition intended to cover an equal range, even one in terms of grasping individuals which can be mentally grasped, will fail. Second, despite the failure of 4.2 we can still assert 5.1 , or the slightly more accurate 7.1 , and we can also hold that in certain cases the having of concepts entails the having of dispositions to act in appropriate nonlinguistic ways, and that in certain cases the having of concepts entails the having of abilities to form parts of nonverbal conceptual thoughts. Thus, we know something of the meaning of conceptualization, even though it can't be said in a single breath as it could if we had a definition. But if a definition in terms of grasping a mentally graspable individual is to be adequate, it must entail all this that we do know so far. If, however, we are told that John is a mental proprietor of a property, an intension, or a universal, we will be unable to say, on this basis, whether John can or cannot use correctly a certain expression, whether or not he is disposed to act in certain ways, and even whether or not he can think nonverbally. Yet it 
might be claimed that the advocates of such a definition understand it in such a way that they can, even though we cannot, answer these questions in every instance in which the definiens is applied. But then it is to be suspected that the expression 'grasps the property...', as applied in any instance, is but a mystifying abbreviation for a list of abilities which are facets of a concept.

\section{NOTES}

13. Cf. Ryle, The Concept of Mind, London, 1949, p. 44. "... higher grade dispositions... are, in general, not single-track dispositions...."

14. To a person who knows no German the definientia of 4.2 and 6.4 will not convey the same things. But to argue from this that the two definientia are not synonymous would, in effect, be to use intersubstitutibility salva veritate in all contexts, including quotations, as a criterion of statement-synonymy. (It is clear that the two definientia are not intersubstitutible salva veritate in every context; for 'Dick understands the sentence 'John can use correctly some expression in some language which is used in the way that 'red' is used in English' may be true even though 'Dick understands the sentence 'John can use correctly some expression in some language which is used in the way that 'rot' is used in German', will be false if Dick knows no German.) Since the two definientia are contingent and are such that, without an appeal to facts and with the instruction that 'rot' in German has the same use as 'red' in English, one could determine that their truth values will be the same, they are synonymous in one permissible sense. This is a sufficiently strong sense of synonymy to dispell any uneasiness in regard to the question of whether the principle used in constructing 4.2 has the paradoxical property of attaching equiform definienda to nonsynonymous definientia. Cf. Church, "On Carnap's Analysis of Statements of Assertion and Belief," Analysis, X, 1950, pp. 97-99; Geach, Mental Acts, Their Content and Their Objects, London, 1957, pp. 8992; and N. L. Wilson, The Concept of Language, Toronto, 1959, Pp. 123-4.

15. From ' $A$ ' one can derive 'If $M$ then $A$ '. From 'If $M$ then $A$ ', where ' $M$ ' is true a priori, one can derive ' $A$ '. Hence, ' $A$ ' is equivalent to 'If $M$ then $A$ ', where ' $M$ ' is true a priori.

16. Since, here, ' $S$ ' is replaceable by names of sentences and not by names of names of sentences and since ' $p$ ' is replaceable by sentences and not by names of sentences, $U$ and $X$ are not subject to the difficulties noted by Black ("The Semantic Definition of Truth," Analysis, VIII, 1948, pp. 49-63) and Geach ("Designation and Truth," Analysis, VIII, 1948, Pp. 93-6). Similarly, neither are 6.1 and 6.2 , since ' $E$ ' is not 
replaceable by names of names of expressions and ' $e$ ' is not replaceable by names of expressions in italics.

17. Cf. N. Wolterstorff, "Are Properties Meanings?" Journal of Philosophy, LVII, 1960, pp. 277-81.

18. No emendation would be required if predicates ('sweet', 'red',....) were synonymous with the corresponding property descriptions in which they occur in italics ('the property sweet', 'the property red',...). Carnap thinks it an advantage to regard 'sweet' (or ' $S$ ') and 'the property sweet' (or ' $S \hat{x}$ ') as having both the same extension and the same intension (Meaning and Necessity, Chicago, 1947, 4-16, 4-17, p. 19; 26-5, 26-6, p. 108). Having the same intension they are L-equivalent (Ibid., 5-2, p. 23). According to "the method of the name-relation" (Ibid., \#\#24-26), 'the property sweet' and 'the taste of Aunt Mary's specialty' can be said to name the property sweet. But Carnap's pattern is to treat the property which, under the method of the name-relation, is named by an expression as its intension. Thus the intension of 'the taste of Aunt Mary's specialty' is the property sweet. 'the property sweet' and 'the taste of Aunt Mary's specialty' are then Lequivalent. But this is clearly not the case. In view of this consequence, one cannot claim that a predicate and its corresponding property description in which it occurs in italics are synonymous on the grounds that the intension of a property description is the property it describes.

University of Notre Dame

Notre Dame, Indiana 